\title{
Southampton
}

School of Social Sciences

School of Social Sciences

Economics Division

University of Southampton

Southampton SO17 1BJ , UK

Discussion Papers in

Economics and Econometrics

Econometrics and Psychometrics - Rivers out of Biometry

J ohn Aldrich

No. 1010

This paper is available on our website

http://www.southampton.ac.uk/socsci/economics/research/papers 


\title{
Econometrics and Psychometrics-
}

\section{Rivers out of Biometry*}

\author{
John Aldrich \\ Economics Division \\ School of Social Sciences \\ University of Southampton \\ Southampton \\ SO17 1BJ \\ UK \\ e-mail: john.aldrich@soton.ac.uk
}

\begin{abstract}
At the beginning of the 20th century economists and psychologists began to use the statistical methods developed by the English biometricians. This paper sketches the development of psychometrics and econometrics out of biometry and makes some comparisons between the three fields. The period covered is 1895-1925.
\end{abstract}

Key names: R. A. Fisher, Karl Pearson, Charles Edward Spearman, Geoffrey Thomson, Sewall Wright, G. Udny Yule.

Keywords: History of econometrics, statistics, biometry, factor analysis, path analysis.

JEL classification: B816

* Based on a contribution to the History of Political Economy Conference on “The History of Econometrics” April 2010.

June 2010 


\section{Introduction}

In 1902 John Pease Norton wrote in the preface to his study of the New York money-market, "Although Professor Pearson's writings have been largely in connection with the biological problems of evolution, his statistical methods have been found to apply satisfactorily to the problems presented under the theory of money and credit." In 1904 Charles Edward Spearman advocated a "Correlational Psychology" in which Pearson's formula for correlation had a central place.

The period 1895-1925 saw the origins and establishment of the fields that came to be called econometrics and psychometrics. I consider what these fields owed to biometry-the statistical approach to the biological problems of evolution-and make some comparisons between all three. My history concentrates on the developments in biology and psychology as they are less familiar to historians of econometrics. These developments are interesting to contemplate for the biometricians and psychometricians were already discussing issues associated with the respective roles of statistical analysis and of subject matter theory, issues that became prominent in econometrics only much later.

The early psychometricians and econometricians learnt correlation from Pearson (1896), a technical paper he read to the Royal Society in 1895 , or from the second edition of his book on philosophy of science, The Grammar of Science (1900a). The paper showed how by the use of the multivariate normal distribu- 
tion and correlation "such subjects as inheritance, regression, assortative mating and panmixia, are capable of perfectly direct quantitative treatment." Pearson's (1896, p. 318) belief was that such a treatment "alone can settle the chief problems of evolution." Pearson's project was studiedly descriptive but the "rediscovery of Mendel" in 1900 posed the question of whether the biometricians' correlations had a structure grounded in Mendel's laws. Running in parallel to this debate was one in psychology about whether correlations between test scores reflected a particular structure in human abilities. At the time the parallel was not perceived and nor, of course was the term "structure" used-it was popularised in the 1940s by the Cowles econometricians who saw affinities between their work and that of the biometricians and the psychometricians.

\section{Describing inheritance}

"Regression, heredity and panmixia" was the third of Pearson's "Mathematical Contributions to the Theory of Evolution"-a series that ran to 19 parts. Karl Pearson (1857-1936) was professor of applied mathematics and mechanics at University College London and he had been collaborating with the zoologist Raphael Weldon (1860-1906) since 1891. For a sketch of Pearson's life and a guide to the literature see Aldrich (2003/10).

The paper was Pearson's attempt to summarise and extend Galton's work on 
regression and correlation. Natural Inheritance (1889) was the current big work by Francis Galton (1822-1911) but his ambition of to create a quantitative science of heredity was first evident in his work on mankind, Hereditary Genius (1869): Galton's work has been discussed from the viewpoints of the history of statistics by Stigler (1986, Part 3) and of the history of biology by Bulmer (2003). An early contribution, "Typical laws of heredity" (1877a), formalised the notion of "reversion" as a stable first order autoregressive process with a generation as the unit of 'time'. Reversion did not travel beyond the study of heredity although Galton (1877b, p. 202) found Jevons a parallel in political economy in "the successive stages by which overproduction of any commodity reverts to one of normal production."

A decade after reversion (regression) came co-relation (correlation). Galton (1888, p. 135) introduced it as follows:

Two variable organs are said to be co-related when the variation of the one is accompanied on the average by more or less variation of the other, and in the same direction. [...] It is easy to see that co-relation must be the consequence of the variations of the two organs being partly due to common causes. If they were wholly due to common causes, the co-relation would be perfect, as is approximately the case with the symmetrically disposed parts of the body. 
Galton drew others into correlation: Weldon correlated measurements on crustaceans and the political economist F. Y. Edgeworth (1845-1926) generalised the theory using the multinormal distribution; see Stigler (1986, chs. $9 \& 10$ ) for details.

The variations considered in "Regression, heredity and panmixia" "obey the normal law of frequency." Pearson (1896, pp. 261-3) considers a "complex" of measurable characteristics, $\eta_{1}, \eta_{2}, \ldots, \eta_{n}$ for which the "law of frequency" is

$$
P=C e^{-\frac{1}{2} \chi^{2}} \delta \eta_{1} \delta \eta_{2} \ldots \delta \eta_{n}
$$

where $\chi^{2}$ is a quadratic function of the $\eta^{\prime} s$. Pearson does not postulate the multivariate normal directly but derives it on the assumption that the observable $\eta^{\prime} s$ depend upon "an indefinite number of quite inappreciable and unascertainable contributory causes":

$$
\begin{aligned}
\eta_{1}= & \alpha_{11} \epsilon_{1}+\alpha_{12} \epsilon_{2}+\alpha_{13} \epsilon_{3}+\ldots+\alpha_{1 m} \epsilon_{m} \\
\eta_{2}= & \alpha_{21} \epsilon_{1}+\alpha_{22} \epsilon_{2}+\alpha_{23} \epsilon_{3}+\ldots+\alpha_{2 m} \epsilon_{m} \\
& \ldots \\
\eta_{n}= & \alpha_{n 1} \epsilon_{1}+\alpha_{n 2} \epsilon_{2}+\alpha_{n 3} \epsilon_{3}+\ldots+\alpha_{n m} \epsilon_{m} .
\end{aligned}
$$

where the $\epsilon^{\prime} s$ are independent normal variables. The idea is that there is correlation 
between the observable $\eta^{\prime} s$ because some of the $\epsilon^{\prime} s$ are common to parent and offspring.

Pearson's contributory causes are Galton's common causes and the use of an indefinite number to establish the multivariate normal resembles the use of "elementary errors" to establish the univariate normal in the theory of errors, except that in the latter case a central limit theorem is applied to non-normal quantities. Pearson's (p. 262) contributory causes may be

magnitudes of other organs not in the complex, variations in environment, climate, nourishment, physical training, various ancestral influences and innumerable other causes which cannot be individually observed or their effects measured.

One important point for later is that Pearson did not suggest that statistical analysis of the observables could make the magnitudes of the contributory causes or their efficacy-the $\alpha^{\prime} s$-accessible.

Pearson (1896, p. 292) makes very limited aims for his analysis:

[the] formulae [...] make not the least pretence to explain the mechanism of inheritance. All they attempt is to provide a basis for the quantitative measure of inheritance-a schedule, as it were, for tabulating and appreciating statistics. 
In the terminology of Koopmans and Reiersøl (1950), Pearson was concerned with "population" characteristics, not "structural" ones.

Pearson's (1896, p. 259) population analysis rested on definitions like this: "Heredity.-Given any organ in a parent and the same or any other organ in its offspring, the mathematical measure of heredity is the correlation of these organs for pairs of parent and offspring." . The biological concepts are expressed in terms of the parameters of the $\eta$ distribution. Thus the simplest case (p. 268) is uniparental inheritance: if the parent deviates by $h$ from the population mean and $x$ is the corresponding value in the offspring, the joint distribution is

$$
z=\frac{N}{2 \pi \sigma_{1} \sigma_{2} \sqrt{1-r^{2}}} e^{-\frac{1}{2}\left\{\frac{x^{2}}{\sigma_{1}^{2}\left(1-r^{2}\right)}-\frac{2 r x h}{\sigma_{1} \sigma_{2}\left(1-r^{2}\right)}+\frac{h^{2}}{\sigma_{2}^{2}\left(1-r^{2}\right)}\right\}} .
$$

The offspring have "variation following a normal distribution about the mean

$$
x_{0}=r \frac{\sigma_{1}}{\sigma_{2}} h
$$

and $[\ldots]$ by our definition, the coefficient of regression $=x_{0} / h=r \sigma_{1} / \sigma_{2} . "$

The $\eta / \epsilon$ analysis was not adopted by other writers or developed by Pearson himself but one part of his paper was very influential: Pearson introduced the product-moment formula for correlation and settled the estimation issue. The formula was generally adopted, as were the formulae for large-sample standard errors 
that Pearson developed. Pearson's justification of the "most probable" value was unclear and changed over time-see Aldrich (2008)-but the formulae went unaltered into the era of maximum likelihood inaugurated by Fisher (1922a). Ronald Aylmer Fisher (1890-1962) was responsible for completing the inference wing of the correlation edifice when he derived the exact distribution of the correlation coefficient in 1915, of the partial correlation coefficient in 1921 and of the multiple correlation in 1928. In the course of the 1920s Fisher replaced Pearson as the leader of biometry and of English statistics; for Fisher see the biography by Box (1978) and the annotated bibliography by Aldrich (2003/10).

Pearson (1896) did not only provide a theoretical scheme for tabulating the statistics of inheritance, in works like Pearson and Lee (1903) he presented the actual "laws of inheritance"-correlations between physical characters based on a sample of a thousand or so relatives. One biometric law of special importance was the "ancestral law" the multiple regression expression of the idea that the character of the offspring can be calculated with more exactness, the more extensive our knowledge of the corresponding characters of the ancestry.

Pearson's formulae soon appeared in textbooks: Bowley (1901) presented them to statisticians, i.e. to economic and vital statisticians, Davenport (1904) to biologists, Elderton (1907) to actuaries, Myers (1909) to psychologists and Yule (1911) to anybody. Generally the textbooks confined themselves to the level of describ- 
ing populations, although Yule discussed breakdowns of interpretation, "illusory" correlations; their story is told in Aldrich (1995). None of the textbooks went into structural interpretations of correlations although these soon became matters of intense debate in genetics and psychology; see Sections 4 and 6 below.

\section{Regression, catenas of causation and economics}

While Pearson was writing about correlation and regression in biology, his student/collaborator/colleague, G. Udny Yule (1871-1951), was publishing in economics. Stigler (1986, ch. 10) describes his work and Aldrich (2010a, -b) looks at his relationship with the economists; Kendall (1952) recounts Yule's career and has a bibliography.

Yule developed the Pearson scheme in three respects-by introducing the concept of partial correlation, by relaxing the multinormal assumption for the joint distribution of the observables and by devising new causal interpretations. Pearson was very conscious that his scheme was restricted to jointly normal variables; his previous mathematical contributions (1895) was on skew curves and he projected a scheme for analysing skew correlation. However Pearson never produced a satisfactory theory and indeed continuous multivariate analysis still largely rests on the multinormal distribution. Stigler (1986, pp. 345-58) describes how Yule got round the skew correlation impasse by using results on least squares. The Yule 
regression analysis of the 1890s proved to be a temporary compromise between Pearson and Gauss but the more enduring Fisher fixed $x$ regression analysis of the 1920s was Gauss modernised to include $t$-tests and $F$-tests; for an account see Aldrich (2005).

Yule's thinking about the interpretation of correlations can be seen evolving in his three treatments-(1895, -6 and -9)-of the relationship between the incidence of pauperism in the unions (districts) of England and Wales and the way the Poor Law was administered in them. From the beginning Yule was interested in the possibility that the positive correlation reflected a causal connection but he never used Pearson's scheme of dependence on common causes to rationalise it. At first he (1895, note 2 , p. 605) was doubtful:

[The statement of a positive correlation] does not say either that the low mean proportion of out-relief is the cause of the lesser mean pauperism or vice verse: such terms seem best avoided where one is not dealing with a catena of causation at all. To use a simile, due I believe to Professor Marshall, the case is like that of a lot of balls-say half a dozen-resting in a bowl. Then you cannot say that the position of ball No. 3 is the cause of the position of No. 5 or the reverse. But the position of 3 is a function of the positions of all the others including 5 ; and the position of 5 is a function of the positions of all the others 
including 3: hence variations in the positions of the two balls will be correlated, and it is to this term that I prefer to adhere. To be quite clear, I do not mean simply that out relief determines pauperism in one union and pauperism out-relief in another, so that you cannot say which is which in the average: but I mean that out-relief and pauperism mutually react in one and the same union.

Marshall (1890, p. 534) had criticised Jevons for insisting on a "catena" of causation, instead of representing "supply price, demand price and amount produced as mutually determining one another."

The simplest representation of mutual reaction is the simultaneous equations model

$$
\begin{aligned}
& \eta_{1}=\beta_{12} \eta_{2}+\epsilon_{1} \\
& \eta_{2}=\beta_{21} \eta_{1}+\epsilon_{2}
\end{aligned}
$$

(cf. Haavelmo (1943, p. 2)) but Yule he did not develop such a model. Indeed he dropped the mutual reaction line entirely to consider (1896, p. 620) whether the correlation might express the influence of a third variable, an observable common cause:

My two notes have shown distinctly that there is a connection, but do 
not show whether it is direct, or whether, e.g., I must simply attribute the result, that pauperism is positively correlated with out-relief, to the fact that pauperism and out-relief are both positively correlated with poverty.

To decide this question he introduced and used partial correlations ("net coefficients").

Yule's final pieces on pauperism was a large multiple regression exercise which (1899, p. 251) concentrated on the issue of direct versus indirect influence and attempted to answer the following questions:

(1.) Taking each of the two decades $1871-81,1881-91$, to find by discussion of the changes in all the unions of the country, whether the changes in administration had a direct influence on the changes in pauperism, and, if so, to what extent.

(2.) If the changes in administration had such a direct influence, to find what proportion of the total change in each decade might be ascribed to changes in administration, and what proportion to other changes.

Yule used the regression equation to decide the matter of direct influence as follows

Any double interpretation is now-very largely at all events-excluded. It cannot be argued that the changes in pauperism and out-relief are 
both due to the changes in age distribution, for that has been separately allowed for in the third term on the right; $b \times$ (change in proportion of out-relief) gives the change due to this factor when all the others are kept constant.

See Stigler (1986, pp. 355ff.) for an account what was "in its way a masterpiece."

Correlation had come to economics but the work of Bowley (1901), Norton (1902), Persons (1908), Irving Fisher (1911) and Moore (1911) was based on bivariate analysis and multiple regression only came into general use in the late 1920s. Sometimes the correlation signified a direct causal connection-as in Bowley's investigation of the correlation between the marriage rate and prosperity-and sometimes it simply measured covariation. Attempts to treat

\section{Mendel rediscovered}

In the 1860s when Galton was investigating genius in humans, Gregor Mendel (1822-1884) was propagating peas. When Mendel's results were "rediscovered" in 1900 the biometricians reacted in two ways-by investigating the relationship between Mendelian principles and biometrically established facts and by producing statistical techniques that could be used in Mendelian research. The reconciliation of Mendelism and biometry is one of the most famous passages in the history of biology-see e.g. Provine (1972), Bowler (1989) and Gayon (1998)-but the devel- 
opment of statistical technique in genetics is not so well known.

In England there was a collision between Mendel's champion, William Bateson (1861-1926), and Pearson and Weldon. Bateson had a low opinion of biometric work and did not undertake any detailed investigation of the relationship between Mendel's findings and the patterns obtained by the biometricians. The task was done by people-Pearson, Yule and Fisher--who accepted the biometric results. At first sight Mendelian principles seemed incompatible with the established facts about ancestry, or so Weldon (1902, p. 252) thought:

The fundamental mistake which vitiates all work based upon Mendel's method is the neglect of ancestry, and the attempt to regard the whole effect upon offspring, produced by a particular parent, as due to the existence in the parent of particular structural characters.

Bateson (1902, p. 114) actually agreed-Mendel's Laws are "absolutely at variance with all the laws of ancestral heredity however formulated."

In his review of Bateson's book Yule (1902) took great exception to the polemics but he went on to produce the first examination of the consequences for population outcomes of Mendelian principles. He (1902, p. 236) concluded by insisting

It is, however, essential, if progress is to be made, that biologistsstatistical or otherwise-should recognise that Mendel's Laws and the Law of Ancestral Heredity are not necessarily contradictory statements, 
one or other of which must be mythical in character, but are perfectly consistent the one with the other and may quite well form parts of one homogeneous theory of heredity.

Yule did not really confront the two systems of ideas-he looked for an accommodation between them.

Pearson responded to Bateson with his own essay in theoretical population genetics (1904). Pearson had insisted that the formulae developed in his big correlation paper-see Section 2 above-were descriptive and not explanatory but, as he (1904, p. 85) now explained, they still had a bearing on explanatory theories:

[The] biometric or statistical theory of heredity does not involve a denial of any physiological theory of heredity, but it serves in itself to confirm or refute such a theory. Mendelian formulae analytically developed for randomly mating populations are either consistent or not with the biometric observations on such populations. If they are consistent, it shows their possibility, but does not prove their necessity. If they are not, it shows they are inadequate.

On examination the gross incompatibility that Weldon and Bateson saw disappeared, yet still Pearson's (1904, p. 85) verdict was against Mendelian theory:

The present investigation shows that in the theory of the pure gamete there is nothing in essential opposition to the broad features of linear 
regression, skew distribution, the geometric law of ancestral correlation, etc., of the biometric description of inheritance in populations. But it does show that the generalised theory here dealt with is not elastic enough to account for the numerical values of the constants of heredity hitherto observed.

For Pearson the triumphant later developments involved investing the theory with enough elasticity for it to account for the observed numerical values-it was as though he were in the presence of a "degenerating research programme." Deeper explanations for Pearson's resistance are considered by Morrison (2002) and Tabery (2004) considers Yule's position in more detail.

Yule (1907) responded to the results in Pearson (1904) by arguing that the theory Pearson tested was unduly specialised. Yule (p. 141) saw no difficulty in accounting for the troublesome correlation values: a value of 0.5 "probably indicates an absence of the somatic phenomenon of dominance. In the case of characters like stature, span, \&c. in man this does not seem very improbable." There was a respect in which Yule's 1907 note widened the scope of the discussion:

A complete theory of heredity should take into account, besides germinal processes, the effect of the environment in modifying the soma obtained from any given type of germ-cell-an effect which is hardly likely to be negligible in the case of such a character as stature. This 
may be done without much difficulty for the limited case discussed.

There were no environmental variables for Yule treated the effect of the environment as an unobservable. From his analysis he (1907, p. ) concluded that

The common ratio of the ancestral coefficient remains, however, unaltered at its former value of $\frac{1}{2}$. So far as the coefficients of correlation are concerned, it is accordingly impossible to distinguish between the effect of the heterozygote giving rise to forms that are not strictly intermediate, and the effect of the environment in causing somatic variations which are not heritable.

A paper by Ronald Fisher brought the discussion to an end. "The Correlation Between Relatives on the Supposition of Mendelian Inheritance" (1918a) was written in 1915 but already as an undergraduate in 1911 Fisher had his own synthesis of Bateson and Pearson; see his (1911). "The Correlation Between Relatives" derives a whole set of correlations between off-spring, parents and ancestry and compares them with those published by Pearson and Lee (1903), concluding (p. 433) "In general, they hypothesis of cumulative Mendelian factors seems to fit the facts very accurately." It was as though the $\eta / \epsilon$ analysis of Pearson (1896) had been realised with the $\epsilon^{\prime} s$ as binary Mendelian factors and by an application of the central limit theorem. Fisher's paper is much more ambitious and difficult than 
the earlier work by Pearson and Yule; Provine (1971, pp. 143-7) gives an overview and Moran and Smith (1966) a detailed commentary.

Fisher (1918a, p. 399) introduced the term "variance" explaining that he preferred to work with this quantity rather than with the standard deviation because variances may be added and "we may ascribe to the constituent causes fractions, or percentages, of the total variance which they together produce." Fisher's nontechnical account for the Eugenics Review had the less hypothetical title, "Causes of human variability" (1918b). There he (1918b, p. 214) explains what is meant by a "cause of variability":

in a population absolutely uniform in regard to other causes, such as breeding and exercise, existing differences of nutrition would produce a certain variability-in fact that a certain percentage of the variance must be ascribed to nutrition.

In the main paper Fisher (1918a, p. 401) writes that

[Yule] shows the similarity of the effects of dominance and of environment in reducing the correlations between relatives, but states that they are identical, an assertion to which, as I shall show, there is a remarkable exception, which enables us, as far as existing statistics allow, to separate them and to estimate how much of the total variance is due to dominance and how much to arbitrary outside causes. 
Fisher (1918a, pp. 423-4) presents his estimates of the relative importance of dominance and environment in height using the Pearson and Lee data, concluding

These determinations are subject to considerable errors of random sampling, but our figures are sufficient to show that $[\ldots]$ it is very unlikely that as much as 5 per cent. of the total variance is due to causes not heritable, especially as every irregularity of inheritance would, in the above analysis, appear as such a cause.

Fisher (1918a) was refereed for the Royal Society by Pearson and the prominent Mendelian, Reginald Punnett (1875-1967), and they were not enthusiastic. Pearson thought that the decision to publish "should depend on Mendelian opinion as to the correspondence of the author's hypotheses with observation, and the probability that Mendelians will accept in the near future a multiplicity of independent units not exhibiting dominance or coupling" (Norton and Pearson (1976, p. 154)) while, for Punnett, the exercise was "too much of the order of problem that deals with weightless elephants upon frictionless surfaces, where at the same time we are largely ignorant of the other properties of the said elephants and surfaces" (p. 155). When Fisher sent Pearson a copy of the published work, the latter replied, "Many thanks for your memoir which I hope to find time for. I am afraid I an not a believer in cumulative Mendelian factors as being the solution of the heredity puzzle." (E. S. Pearson (1968, p. 456)). In 1918 Fisher was a school master but he 
had the satisfaction of succeeding Pearson as Professor of Eugenics at University College in 1932 and Punnett as Arthur Balfour Professor of Genetics at Cambridge in 1943.

\section{$5 \quad$ Statistical methods in genetics}

For different reasons Pearson, Yule and Fisher worked to derive the correlations associated with Mendelian models of reproducing populations. In their theoretical exercises observed correlations were treated as known without error and so there was no statistical inference in the technical sense. There were other meetings of biometry and Mendelism which did involve statistical inference. One stream runs from with Weldon's (1902, p. 235) application of Pearson's (1900b) $\chi^{2}$ goodness of fit test to Mendel's results on alternative inheritance in peas. Weldon wrote as a critic but biometricians more sympathetic to Mendelism adapted their methods to its requirements; the American botanist and Biometrika author J. Arthur Harris (1912) applied the goodness of fit test to Mendelian ratios associated with the phenomenon of coupling of, or linkage between, genes. Structural estimation soon followed: Engledow and Yule (1914) considered a structured multinomial population where the four theoretical probabilities (corresponding to two forms of two characters) are given by 


$$
\begin{array}{llll}
A B & A b & a B & a b \\
p^{2}+0.5 & 0.25-p^{2} & 0.25-p^{2} & p^{2}
\end{array}
$$

where the parameter $p$ measures the degree of coupling. To estimate $p$ Engledow and Yule (1914, p. 42) improvised a method later called minimum $\chi^{2}$. They produced an ad hoc solution to a specific problem but when Fisher (1922b) applied maximum likelihood to the estimation of linkage he had the general theory of Fisher (1922a) behind him. Fisher used the estimation of linkage to illustrate the method of maximum likelihood in his manual, Statistical Methods for Research Workers (1925). The scheme is more elaborate than that of Engledow and Yule for there are two parents with possibly different degrees of linkage. In Engledow and Yule the parameter $p$ enters in the form of $p^{2}$ but in Fisher (1925, p. 24) $p^{2}$ is replaced by the product of the parental terms; in the second edition Fisher (1928, p. 241) explained that the male and female parameters are not separately identified-as the saying would later go. The history of the estimation of linkage is treated by Edwards (1996 and 2005).

There was also a stream of genetically informed correlation analysis. The American zoologist Sewall Wright (1889-1988) was a major contributor. Wright had no connection with the English biometric community and was unaware of the Pearson-Yule-Fisher discussion but he had a basic knowledge of correlation and could see how the technique could be applied in Mendelian research. Wright 
developed a scheme resembling Spearman's factor analysis in his "On the nature of size factors" (1918) and his "Relative importance of heredity and environment in determining the piebald pattern of guinea-pigs" (1920) introduced the method of path coefficients that he would promote for the rest of his life. There was some overlap between the 1920 paper and Fisher's "Correlation between relatives"Li (1968) also brings out the similarity in technique-but, while Fisher did not extract a general approach, Wright did and, beginning with his (1925), tried to persuade economists to adopt it. For Wright in biology see Provine (1986) and, for path analysis specifically, Wolfle (1999) and Steffes (2007); for his campaign in econometrics see Goldberger (1972) and Stock and Trebbi (2003)

The collision-or confluence-of biometry and Mendelism gave rise to two forms of structural inference: studies in theoretical population genetics which took the facts as described by the parameter values of a multinormal distribution as given and asked whether a Mendelian interpretation could be given; Mendelian research in which parameters based on over-identified multinomial distributions or-in the case of path analysis-exactly identified multinormals. There was some parallel activity in psychology, although there the over-identified distributions were multinormal and not multinomial. Structural estimation with over-identified multinormals came to econometrics to settle with Haavelmo (1943). 


\section{Factors and their reality}

Charles Edward Spearman (1863-1945) was a career soldier who turned to psychology in his mid-thirties. The study of "the abilities of man" (the title of his 1927 treatise) was his life work and his "General intelligence" of 1904 was the first draft. In 1907 he joined the University College department of philosophy and psychology to become colleague of a kind to Karl Pearson; in the beginning Yule was also present as Newmarch Lecturer in statistics. For a biography of Spearman see Lovie and Lovie (1996) and, for broader perspectives, Cowles (2001) and Boring (1950).

Spearman appears to have taught himself statistics and his two papers (1904a and -b) demonstrate a good command of the correlation techniques of Pearson and Yule. Pearson was never satisfied with Spearman's work but Yule was impressed enough to include the results of the (1904a) analysis of the effects of measurement error on correlation in the Introduction (1911, p. 209). The idea of latent variables measured with error underpinned Spearman's analysis of "general intelligence." Bartholomew (1995, p. 212) gives this assessment of Spearman's factor analysis:

Spearman's great contribution lies in his recognition that one could introduce latent variables into scientific discourse through their relationship with manifest variables. The technical apparatus which he introduces to do this seems, in retrospect, crude and limited and his 
concern with a particular substantive issue made it difficult for him to see the full potential of what he had done.

"General intelligence" (1904b) is a long paper which includes a wide-ranging survey of previous attempts to characterise intelligence but, while the drift of the statistical argument is clear, the details are obscure; Vincent (1954) attempts to reconstruct them. Spearman wished to understand what was behind a correlation table such as the following based on scores from tests of mental abilities (1904b, p. 275):

Classics French English Maths Discrim Music

$\begin{array}{lcccccc}\text { Classics } & & 0.83 & 0.78 & 0.70 & 0.66 & 0.63 \\ \text { French } & 0.83 & & 0.67 & 0.67 & 0.65 & 0.57 \\ \text { English } & 0.78 & 0.67 & & 0.64 & 0.54 & 0.51 \\ \text { Maths } & 0.70 & 0.67 & 0.64 & & 0.45 & 0.51 \\ \text { Discrim } & 0.66 & 0.65 & 0.54 & 0.45 & & 0.40 \\ \text { Music } & 0.63 & 0.57 & 0.51 & 0.51 & 0.40 & \end{array}$

With few exceptions each correlation is greater than any to the right of it in the same row, or below it in the same column.

Spearman perceived a structure consisting of a general factor underlying all the skills and factors specific to the skills; the hierarchy reflected the degree to which the tests measured this general factor. Thus he (1904b, p. 284) drew these conclusions: 
IV. The above and other analogous observed facts indicate that all branches of intellectual activity have in common one fundamental function (or group of functions), whereas the remaining or specific elements of the activity seem in every case to be wholly different from that in all the others. The relative influence of the general to the specific function varies in the ten departments here investigated from 15:1 to 1:4.

V. As an important practical consequence of this universal Unity of the Intellectual Function, the various actual forms of mental activity constitute a stably interconnected Hierarchy according to their different degrees of intellective saturation.

Spearman did not present any algebra but the modern way of presenting his scheme was available by specialising the $\eta / \epsilon$ analysis of Pearson (1896)-see Section 2 above-and expressing the performance on the $i$-th test by

$$
\eta_{i}=\alpha_{i} \epsilon_{0}+\epsilon_{i}
$$

Although Spearman (1904b, p. 225) gave Pearson (1896) as his reference for the product-moment formula, he did not pick up the $\eta / \epsilon$ analysis. Conceptually, of course, Pearson and Spearman were worlds apart for Pearson held the $\epsilon^{\prime} s$ to be "unascertainable" and indefinite in number. 
The variances and covariances (as Fisher would have called them) are given by

$$
\begin{aligned}
\operatorname{var}\left(\eta_{i}\right) & =\alpha_{i}^{2} \sigma_{0}^{2}+\sigma_{i}^{2} \\
\operatorname{cov}\left(\eta_{i}, \eta_{j}\right) & =\alpha_{i} \alpha_{j} \sigma_{0}^{2} .
\end{aligned}
$$

Spearman expressed the implied restrictions in terms of correlations: for any four scores, the "tetrad difference" $r_{i k} r_{j l}-r_{i l} r_{j k}$, is equal to 0, a condition Spearman and Hart (1912, p. 58) derived from the absence of correlation between scores when the general factor $\epsilon_{0}$ is partialled out. The scheme and its extensions gave plenty of scope for devising estimation and testing routines.

The universality of Spearman's scheme could be challenged by finding data that exhibited no hierarchy, as by Wood (1910). Thomson raised an objection, more theoretical than empirical. Godfrey Hilton Thomson (1881-1955) was the second figure in English psychometrics. He originally studied mathematics and physics and he taught himself statistics so well that Pearson offered him a job and published three of his papers in Biometrika. In a string of articles published in 1916-19 Thomson emphasised that the Spearman structure is not the only one that would generate such a hierarchy in the correlations: Spearman's statistical results were no "proof" of the "existence of general ability" (1919) as it is possible to have a "hierarchy without a general factor" (1916). With the benefit of the concepts and formalism introduced in the 1940s the task may now seem an easy exercise in 
matrix algebra but Thomson made the point with Monte-Carlo experiments using dice. Bartholomew, Deary and Lawn (2009) have a full account of Thomson's career.

Pearson and Yule kept an eye on what others did with correlation; Fisher (1920/1 and 1923/4) also monitored activity in psychology. Reviewing a book by Thomson, Yule (1921, p. 105) gave his verdict on the Thomson-Spearman controversy:

The difficulty is that there may be more than explanation. From the statistical standpoint Dr Spearman's explanation seems to me by far the simplest, but the judgement as to its validity must be based on other grounds.

Pearson reviewed Spearman's Abilities of Man and he (1927, p. 183) was not impressed by the "new Copernican theory"-"It may possibly turn out to be true, but the proof will have to be more rigid than anything provided so far in 'The Abilities of Man."' The chief deficiencies were in the sampling theory of the tetrad differences and Pearson and Moul (1929) set out to repair them.

The econometricians do not appear to have noticed the psychometricians although one economic project had a flavour of factor analysis, the construction of an index of general business conditions. The project had some roots in economics, in particular in index numbers, but there was a new idea-series belong together if 
they move together. The architect of the project, Warren Pearsons, had been an early proponent of correlation and correlation figured in the new project. In his big inaugural paper Persons (1919, p. 132) alludes to the $\eta / \epsilon$ analysis of Pearson (1896) but rejects it because economic time series are too dissimilar to the statis-

tical series of Galton and Pearson. In his analysis Persons tried to accommodate the time-series patterns of movement and co-movements and, unlike Spearman, did not come close to formalising what he was doing; see Morgan (1990, pp. 5663) for an account of the project. Later, when psychological factor analysis was better known, it provided an entry into the subject of business barometers; see Rhodes (1937).

\section{Futures: divergences and convergences}

In the years before 1925 a number of economists-Bowley, Norton, Moore, Persons and Irving Fisher among them-adopted the new statistical methods of Pearson; see Morgan (1990, passim) and Aldrich (2010a). A number of psychologists made the same move. The economists did not have the same grasp of the theory of correlation and ability to re-imagine the concept as the psychologists Spearman and Thomson. However neither psychometrics nor econometrics stood comparison with biometry. The statistical scene was dominated by Pearson-and then R. A. Fisher-and their statistical work was so much a product of their interest in heredity 
and evolution that psychometrics and econometrics were completely overshadowed.

From the work of Pearson and Yule-and after 1925 from Fisher-a bundle of statistical ideas was extracted and circulated. This had no room for structural reasoning involving genes and factors-this belonged to the substantive disciplines and was not easily accessible to outsiders. Factor analysis had a high barrier to entry but it was low compared to that for biometry. There appear to have been few exchanges between biology, economics and psychology: nearly all of the exchanges were with the statistical hub so that only people there-Pearson, Yule and later Fisher-could see what was going on in more than one field.

The arrival of Frisch, Hotelling and Schultz around 1925 raised the level of statistical sophistication in economics; see Aldrich (2010a) for references. By the 1930s econometrics matched psychometrics in statistical sophistication and in Frisch's confluence analysis it had something as talismanic as factor analysis. There was still a lag behind biometry: Fisher used maximum likelihood to estimate linkage in 1922 but it arrived in econometrics and psychometrics only much later-in the work of Koopmans (1937) and Lawley (1940).

In the 1930s the University of Chicago replaced University College as the centre for applied correlation with L. L. Thurstone in psychology, H. Schultz in economics and S. Wright in genetics. In the 1940s the Cowles Commission brought together identification in the simultaneous equations model and in factor analysis-see Koop- 
mans and Reiersøl (1950)-and there was nothing surprising in Anderson and Rubin writing on both limited information maximum likelihood (1949) and inference in factor models (1956). Factor analysis and stochastic equations both appear in the concluding further topics chapter of Anderson's Multivariate Analysis (1958). Goldberger (1971) looked out from econometrics to psychometrics and Goldberger (1972) looked at path analysis, in response to the interest sociologists were showing in the topic-see Blalock (1961) and Duncan (1966).

In long-run the metaphor of rivers out of biometry lost any validity. In the English statistics of Pearson and Fisher-roughly 1890-1940-biometry was the central discipline but in American mathematical statistics in the age of Wilks, Hotelling, Neyman and Wald-after 1940-biometry was just another applied field; for references see Aldrich (2010a).

\section{References}

Aldrich, J. (1995) Correlations Genuine and Spurious in Pearson and Yule, Statistical Science, 10, 364-376.

(1997) R. A. Fisher and the Making of Maximum Likelihood 1912-22,

Statistical Science, 12, 162-176.

(2001/10) Karl Pearson: A Reader's Guide, website

http://www.economics.soton.ac.uk/staff/aldrich/kpreader.htm (2003/10) A Guide to R. A. Fisher, website 
http://www.economics.soton.ac.uk/staff/aldrich/fisherguide/rafreader.htm (2005) Fisher and Regression, Statistical Science, 20, 401-417.

(2008) The Enigma of Karl Pearson and Bayesian Inference, unpub-

lished manuscript available on author's website at

http://www.economics.soton.ac.uk/staff/aldrich/KP\%20enigma.pdf (2010a) The Econometricians' Statisticians 1895-1945, History of Po-

litical Economy, 42, 111-154.

(2010b) Mathematics in the London/Royal Statistical Society 1834-

1934, to appear in the Journal Electronique d'Histoire des Probabilités et de la

Statistique.

Anderson, T. W. (1958) An Introduction to Multivariate Statistical Analysis, New York: Wiley.

Anderson, T. W. \& H. Rubin (1949) Estimation of the Parameters of a Single Equation in a Complete System of Stochastic Equations, Annals of Mathematical Statistics, 20, 46-63.

(1956) Statistical Inference in Factor Analysis, pp. 111-150 in Proceedings of the Third Berkeley Symposium on Mathematical Statistics and Probability, Volume V. Berkeley and Los Angeles: University of California Press.

Bartholomew, D. J. (1995) Spearman and the Origin and Development of Factor Analysis, British Journal of Mathematical and Statistical Psychology, 48, 211-220. 
Bartholomew, D. J., I. J. Deary and M. L. Lawn (2009) Sir Godfrey Thomson: A Statistical Pioneer, Journal of the Royal Statistical Society A, 172, 467-482.

Bateson, W. (1902) Mendel's Principles of Heredity: A Defence with a Translation of Mendel's Original Papers on Hybridisation, Cambridge: Cambridge University Press.

Blalock, H. M. Jr. (1961) Causal inferences in Non-experimental Research, ChapelHill-University of North Carolina Press.

Boring, E. G. (1950) A History of Experimental Psychology, second edition, New York: Appleton-Century-Crofts.

Bowler, P. J. (1989) The Mendelian Revolution: The Emergence of Hereditarian Concepts in Modern Science and Society, London: Athlone Press.

Bowley, A. L. (1901) Elements of Statistics, London: King.

Box, J. F. (1978) R. A. Fisher: The Life of a Scientist, New York: Wiley.

Brown, W. (1910) Some Experimental Results in the Correlation of Mental Abilities, British Journal of Psychology, 4, 296-322.

Brown, W. \& G. H. Thomson (1921) Essentials of Mental Measurement, Cambridge: Cambridge University Press.

Bulmer, M. (2003) Francis Galton: Pioneer of Heredity and Biometry, Baltimore: Johns Hopkins University Press.

Cowles, M. (2001) Statistics in Psychology: An Historical Perspective, 2nd edition, 
London: Erlbaum.

Cudeck, R. and R. C. MacCallum (Eds.) (2007) Factor Analysis at 100, Mahwah, NJ: Erlbaum.

Davenport (1904) Statistical Methods with Special Reference to Biological Variations, 2nd. edition, New York: Wiley.

Duncan, O. D. (1966) Path Analysis: Sociological Examples, American Journal of Sociology, 72, 1-16.

Edwards, A. W. F. (1996) The Early History of the Statistical Estimation of Linkage, Annals of Human Genetics, 60, 237-249.

(2005) Linkage Methods in Human Genetics before the Computer, Human Genetics, 52, 399-433.

Engledow, F. L. and G. U. Yule (1914) The Determination of the Best Value of the Coupling-ratio from a Given Set of Data, Proceedings of the Cambridge Philosophical Society, 17, 436-440. Reprinted in Statistical Science, 7, (1997), $42-4$.

Fisher, I. (1911) The Purchasing Power of Money, New York: Macmillan.

Fisher, R. A. (1911) Paper on 'Heredity' (comparing methods of Biometry and Mendelism), unpublished paper reprinted as pp. 155-162 of Norton and Pearson (1976).

(1915) The Frequency Distribution of the Values of the Correlation 
Coefficient in Samples from an Indefinitely Large Population,Biometrika, 10: 213220. (1918a) The Correlation between Relatives on the Supposition of Mendelian Inheritance, Transactions of the Royal Society of Edinburgh, 52, 399-433. (1918b) The Causes of Human Variability, Eugenics Review, 10, 213220. (1920/21) On the Degree of Perfection of Hierarchical Order among Correlation Coefficients. (G. H. Thomson), Eugenics Review, 12, 63. (1922a) On the Mathematical Foundations of Theoretical Statistics, Philosophical Transactions of the Royal Society, A, 222, 309-368. (1922b) The Systematic Location of Genes by Means of Crossover Observations, American Naturalist, 56, 406-411. (1923/24) Recent Contributions to the Theory of "Two Factors". (C. Spearman, Eugenics Review, 15, 446. (1925) Statistical Methods for Research Workers, Edinburgh: Oliver \&

Boyd.

Galton, F. (1869) Hereditary Genius, London: Macmillan. (1877a) Typical Laws of Heredity, Proceedings of the Royal Institution of Great Britain, 8, 282-301. (1877b) Letter to W. S. Jevons, reproduced on pp. 200-2 of R. D. C. 
Black (ed) (1977) Papers and Correspondence of William Stanley Jevons, Vol. 4, London: Macmillan.

(1888) Co-relations and their Measurement, Proceedings of the Royal

Society, 45, 135-145.

(1889) Natural Inheritance, London: Macmillan.

Gayon, J. (1998) Darwinism's Struggle for Survival: Heredity and the Hypothesis of Natural Selection, Cambridge: Cambridge University Press

Goldberger, A. S. (1971) Econometrics and Psychometrics: A Survey of Communalities, Psychometrika, 36, 83-107.

(1972) Structural Equation Methods in the Social Sciences, Economet-

rica, 40, 979-1001.

Haavelmo, T. (1943) The Statistical Implications of a System of Simultaneous Equations, Econometrica, 11, 1-12.

Harris, J. A. (1912) A Simple Test of the Goodness of Fit of Mendelian Ratios, American Naturalist, 46, 741-745.

Kendall, M. G. (1952) George Udny Yule C.B.E., F.R.S., Journal of the Royal Statistical Society A, 115, (1), 156-171.

Klein, J. L. (1997) Statistical Visions in Time, Cambridge: Cambridge University Press.

Koopmans, T. C. (1937) Linear Regression Analysis of Economic Time Series, 
Haarlem: Bohn.

Koopmans, T. C. and O. Reiersøl (1950) The Identification of Structural Characteristics, Annals of Mathematical Statistics, 21, 165-181.

Lawley, D. N. (1940) The Estimation of Factor Loadings by the Method of Maximum Likelihood, Proceedings of the Royal Society of Edinburgh, 60, 64-82.

Li, C. C. (1968) Fisher, Wright, and Path Coefficients, Biometrics, 24, 471-483.

Lovie, P. and Lovie A. D. (1996) Charles Edward Spearman F.R.S. (1863-1945)

Notes and Records of the Royal Society of London, 50, 75-88.

Marshall, A. (1890) Principles of Economics, vol. 1, London: Macmillan.

Moore, H. L. (1911) Laws of Wages: An Essay in Statistical Economics, New York: Macmillan.

Moran, P. A. P. and C. A. B. Smith (1966) Commentary on R. A. Fisher's Paper

'The Correlation between Relatives on the Supposition of Mendelian Inheritance'. Eugenics Laboratory Memoirs XLI, Galton Laboratory, University College London. Morgan, M. S. (1990) The History of Econometric Ideas, Cambridge University Press, New York.

Morrison, M. (2002) Modeling Populations: Pearson and Fisher on Mendelism and Biometry, British Journal for the Philosophy of Science, 53, 39-68.

Myers, C. (1909) A Text Book of Experimental Psychology, Cambridge: Cambridge University Press. 
Norton, B. J. and E. S. Pearson (1976) A Note on the Background to, and Refereeing of, R. A. Fisher's 1918 Paper 'On the Correlation between Relatives on the Supposition of Mendelian Inheritance' Notes and Records of the Royal Society of London, 31, 151-162.

Norton, J. P. (1902) Statistical Studies in the New York Money-market, Preceded by a Brief Analysis under the Theory of Money and Credit with Statistical Tables, Diagrams and Folding Chart, New York: Macmillan.

Pearson, E. S. (1968) Some Early Correspondence between W. S. Gosset, R. A. Fisher and Karl Pearson, with Notes and Comments, Biometrika, 55, 445-457.

Pearson, K. (1895) Contributions to the Mathematical Theory of Evolution. II. Skew Variation in Homogeneous Material, Philosophical Transactions of the Royal Society A, 186 343-414.

(1896) Mathematical Contributions to the Theory of Evolution. III. Regression, Heredity and Panmixia, Philosophical Transactions of the Royal Society of London. A, 187, 253-318. (1900a) The Grammar of Science, second edition, London, Walter

Scott.

(1900b) On the Criterion that a Given System of Deviations from the Probable in the Case of Correlated System of Variables is such that it can be Reasonably Supposed to have Arisen from Random Sampling, Philosophical 
Magazine, 50, 157-175.

(1904) Mathematical Contributions to the Theory of Evolution. XII.

On a Generalised Theory of Alternative Inheritance, with Special Reference to Mendel's Laws, Philosophical Transactions of the Royal Society of London, A, 203, 53-86.

(1907) On the Theory of Inheritance of Quantitative Compound Characters on the Basis of Mendel's Laws, by G. U. Yule: A Review, Biometrika, 5, $481-482$.

(1909) On the Ancestral Gametic Correlations of a Mendelian Population Mating at Random, Proceedings of the Royal Society B, 81, 225-229.

(1927) The Abilities of Man: their Nature and Measurement, by Prof. C. Spearman, Nature, 120, 181-183.

Pearson, K. \& A. Lee (1903) On the Laws of Inheritance in Man. I. Inheritance of Physical Characters, Biometrika, 2, 357-462.

Pearson, K. \& M. Moul (1929) The Mathematics of Intelligence. The Sampling Errors in the Theory of a Generalised Factor, Biometrika, 19, 246-291.

Persons, W. M. (1908) The Quantity Theory as Tested by Kemmerer, Quarterly Journal of Economics, 22, 274-289 (1919) The Index of General Business Conditions, Review of Economics and Statistics, 1, 110-205. 
Provine, W. B. (1971) The Origins of Theoretical Population Genetics, University of Chicago Press.

(1986) Sewall Wright and Evolutionary Biology. Chicago: University of Chicago Press.

Reiersøl, O. (1950) On the Identifiability of Parameters in Thurstone's Multiple Factor Analysis, Psychometrika, 15, (1950).

Rhodes, E. C. (1937) The Construction of an Index of Business Activity (with discussion), Journal of the Royal Statistical Society, 100, 18-66.

Sharp, S. (1997) 'Much more at home with 3.999 pupils than with four': the Contributions to Psychometrics of Sir Godfrey Thomson', British Journal of Mathematical and Statistical Psychology, 50, 163-74.

Spearman. C. (1904a) Proof and Measurement of Association between Two Things, American Journal of Psychology, 15, 72-101.

(1904b) "General Intelligence," Objectively Determined and Measured, American Journal of Psychology, 15, 201-293.

(1927) The Abilities of Man, Their Nature and Measurement, New York: Macmillan.

Spearman. C. and B. Hart (1912) General Ability, its Existence and Nature, British Journal of Psychology, 5, 51-84.

Steffes, D. M. (2007) Panpsychic Organicism: Sewall Wright's Philosophy for Un- 
derstanding Complex Genetic Systems, Journal of the History of Biology, 40, $327-361$.

Stigler, S. M. (1986) The History of Statistics: The Measurement of Uncertainty before 1900, Cambridge, MA, and London: Belknap Press of Harvard University Press.

Stock, J. H. and F. Trebbi (2003) Who Invented Instrumental Variable Regression?, Journal of Economic Perspectives, 17, 177-194.

Tabery, J. G. (2004) The "Evolutionary Synthesis" of George Udny Yule, Journal of the History of Biology, 34, 73-101.

Thomson, G. H. (1916) A Hierarchy without a General Factor, British Journal of Psychology, 8, 271-281. (1919) The Proof or Disproof of the Existence of General Ability," British Journal of Psychology, 9, 321-336.

Vincent, D, F. (1954) The Earliest Formulae used in Factor Analysis, American Journal of Psychology, 67, 155-163.

Weldon, W. F. R. (1893) On Certain Correlated Variations in Carcinus Mœnas, Proceedings of the Royal Society, 54, 318-329.

(1902) Mendel's Laws of Alternative Inheritance in Peas, Biometrika,

1, 228-254.

Wolfle, L. M. (1999) Sewall Wright on the Method of Path Coefficients: An An- 
notated Bibliography, Structural Equation Modeling, 6, 280-291.

Wright, S. (1918) On the Nature of Size Factors, Genetics, 3, 367-374.

(1920) The Relative Importance of Heredity and Environment in Determining the Piebald Pattern of Guinea-pigs, Proceedings of the National Academy of Sciences, 6, 320-332.

(1925) Corn and Hog Correlations, Washington, DC: U.S. Department of Agriculture Bulletin 1300.

Yule, G. U. (1895) On the Correlation of Total Pauperism with Proportion of Out-relief, I: All Ages, Economic Journal, 5, 603-611. (1896) On the Correlation of Total Pauperism with Proportion of Outrelief, II: Males over Sixty-five, Economic Journal, 6, 613-623. (1897) On the Theory of Correlation. Journal of the Royal Statistical Society, 60, 812-854. (1899) An Investigation into the Causes of Changes in Pauperism in England, chiefly during the last Two Intercensal Decades (Part I), Journal of the Royal Statistical Society, 62, 249-296.

(1902) Mendel's Laws and their Probable Relations to Intra-racial Heredity. New Phytologist, 1, 193-207, 222-238.

(1906) On the Changes in the Marriage- and Birth-rates in England and Wales during the Past Half Century; with an Inquiry as to their Probable 
Causes, Journal of the Royal Statistical Society, 69, 88-.

(1907) On the Theory of Inheritance of Quantitative Compound Characters on the Basis of Mendel's Laws-A Preliminary Note. Pp. 140-142. Report of the Third International Conference 1906 -on Genetics. London: Spottiswoode. (1911) Introduction to the Theory of Statistics, London: Griffin. (1921) Critical Notice of "The Essentials of Mental Measurement" by W. Brown \& G. H. Thomson, British Journal of Psychology, 12, 100-107. 